\title{
TUMOR GIGANTOCELULAR SINOVIAL DO JOELHO
}

\author{
SYNOVIAL GIANT CELL TUMOR OF THE KNEE
}

Rene Jorge Abdalla', Moisés Cohen ${ }^{2}$, Jezimar Nóbrega ${ }^{3}$, Andrea Forgas ${ }^{4}$

\section{RESUMO}

Tumor gigantocelular sinovial é uma neoplasia benigna, raramente sendo relatada na forma de metástase maligna. A localização mais comum de ocorrer um tumor gigantocelular sinovial é na mão e as mais infrequentes são tornozelo e joelho. No presente estudo os autores têm como objetivo descrever um caso raro de tumor gigantocelular sinovial localizado no joelho e o tratamento escolhido. A artroscopia demonstrou, nesse caso, ser o método ideal para o tratamento da lesão, uma vez que permitiu abordagem pouco agressiva e, ao mesmo tempo, boa visualização de todos os compartimentos da articulação do joelho e a completa ressecção do tumor.

Descritores - Joelho; Tumor gigante celular; Sinovial; Neoplasia

\section{ABSTRACT}

Synovial giant cell tumor is a benign neoplasm, rarely reported in the form of malignant metastasis. Synovial giant cell tumor most frequently occurs on the hand, and, most uncommon, on the ankle and knee. In the present study, the authors describe a rare case of synovial giant cell tumor on the knee as well as the treatment approach. Arthroscopy has been shown, in this case, to be the optimal method for treating this kind of lesion, once it allowed a less aggressive approach, while providing good visualization of all compartments of knee joint and full tumor resection.

Keywords - Knee; Giant cell tumor; Synovial; Neoplasm

\section{INTRODUÇÃO}

\section{Definição}

A sinovite vilonodular pigmentada é uma condição que afeta unicamente as articulações sinoviais. Ela pode se apresentar de forma difusa ou nodular (localizada), assemelhando-se a uma neoplasia. Não se sabe se essa doença é uma neoplasia verdadeira ou uma doença de origem reativa, mas as evidências mais recentes de monoclonalidade sugerem etiologia neoplásica ${ }^{(1)}$.

A doença pode ocorrer tanto em adultos jovens como em idosos e se apresenta mais comumente com sintomas relacionados com a natureza intra-articular da massa $^{(2)}$.

O joelho é a articulação mais comumente envolvida, mas pode ocorrer em qualquer articulação sinovial, incluindo quadril, tornozelo, ombro ou cotovelo. Uma forma poliarticular em crianças também foi registrada ${ }^{(1,3)}$.

\section{EXAME}

Durante o exame são encontradas evidências de derrame ou hemartrose, quando pequenos traumas resultam em hemorragia. No tipo localizado, o bloqueio é comum devido à presença de uma massa intra-articular e, tanto na forma difusa ou localizada, observa-se um arco limitado de movimento. Uma massa palpável geralmente não é observada, a menos que existam manifestações extra-articulares da doença. Mais comumente, a doença extra-articular ocorre na fossa poplítea ou na região dos intercôndilos. Nos casos avançados, são evidentes achados de artrose degenerativa ${ }^{(1,3,4)}$.

\section{IMAGEM}

No estágio inicial da doença, os achados das radiografias simples ou são normais ou demonstram um plano adiposo suprapatelar deslocado, devido a um der-

1 - Doutor em Traumatologia e Ortopedia; Professor do Departamento de Ortopedia e Traumatologia da Unifesp/EPM, São Paulo, Brasil.

2 - Professor Livre-Docente; Chefe do Setor de Traumatologia do Esporte do Departamento de Ortopedia e Traumatologia da Unifesp - EPM), São Paulo, Brasil.

3 - Médico Ortopedista do Centro de Ortopedia e Reabilitação no Esporte-Cecore do Hospital do Coração, São Paulo, Brasil.

4 - Pós-graduando do Departamento de Ortopedia e Traumatologia da Faculdade de Medicina da Universidade de São Paulo, São Paulo, Brasil.

Trabalho realizado no Centro de Estudos do Centro de Ortopedia e Reabilitação no Esporte do Hospital do Coração.

Correspondência: Andréa Forgas, Rua Abílio Soares, 227, cj. 31 - 04005-000 - São Paulo, SP, Brasil. E-mail: deaforgas@gmail.com 
rame articular. Os achados das imagens da ressonância magnética são mais significativos. Uma massa de tecidos moles com áreas alternadas de lacunas de sinal claro e escuro em sequências $\mathrm{T} 1$ e T2 representam o acúmulo de líquido (claro em T2) e gordura (claro em $\mathrm{T} 1$ ), bem como depósitos de hemossiderina dentro dos tecidos moles (escuros tanto em T1 e como em T2), respectivamente ${ }^{(3)}$.

\section{HISTOLOGIA}

Histologicamente, a sinovite vilonodular pigmentada focal é indistinguível de um tumor de células gigantes da bainha do tendão. Uma proliferação de células do tipo sinovial arredondadas está presente com ocasionais células gigantes multinucleadas do tipo osteoclastos, células xantomatosas e células inflamatórias entremeadas por toda a lesão $0^{(2)}$.

\section{TRATAMENTO}

A principal forma de tratamento é a excisão cirúrgica, tanto por meio aberto ou artroscópico. Nenhuma terapia conservadora é considerada eficiente para erradicação da doença. Se não forem tratados, alguns pacientes desenvolvem doença estável, mas a maioria necessitará de tratamento por motivos sintomáticos ou para prevenir a progressão eventual para formação de um cisto erosivo periarticular e subsequente destruição da superfície articular cartilaginosa.

Em cerca de um terço dos casos, evolução agressiva pode ocorrer com várias recorrências, a despeito da ressecção cirúrgica. Nesses casos, a utilização de radiação pode ser considerada e administrada, seja através de um feixe de raios externo ou de sinovectomia por radiação intra-articular. Uma vez que a destruição articular tenha ocorrido, artroplastia total do joelho será o tratamento dos sintomas incapacitantes; entretanto, uma sinovectomia ainda deve ser realizada, já que recorrências após artroplastia total do joelho já foram descritas ${ }^{(5)}$.

\section{CASO CLÍNICO}

Paciente RFM, do sexo feminino, de 36 anos de idade, frequentadora de academia, relata em consultório que havia seis meses sentia-se bem quando, de maneira insidiosa, passou a apresentar dores ocasionais no joelho esquerdo aos médios esforços. Os sintomas passaram a ser acompanhados por sensação de falseio, episódios de travamento e estalos ocasionais.
Durante o exame clínico não foram encontradas massas palpáveis, a amplitude de movimento estava entre $0^{\circ}$ e $130^{\circ}$. A dor à palpação da interlinha articular medial esteve presente e não foi encontrado nenhum sinal de instabilidades.

Foram realizados estudo radiográfico e ressonância magnética do joelho. se Observou-se que as radiografias foram normais (Figura 1) e a ressonância revelou imagem nodular na porção profunda da gordura de Hoffa, entre o ligamento transverso e o ligamento cruzado anterior, medindo 1,8 x 1,3cm (Figura 2A, 2B, 2C).

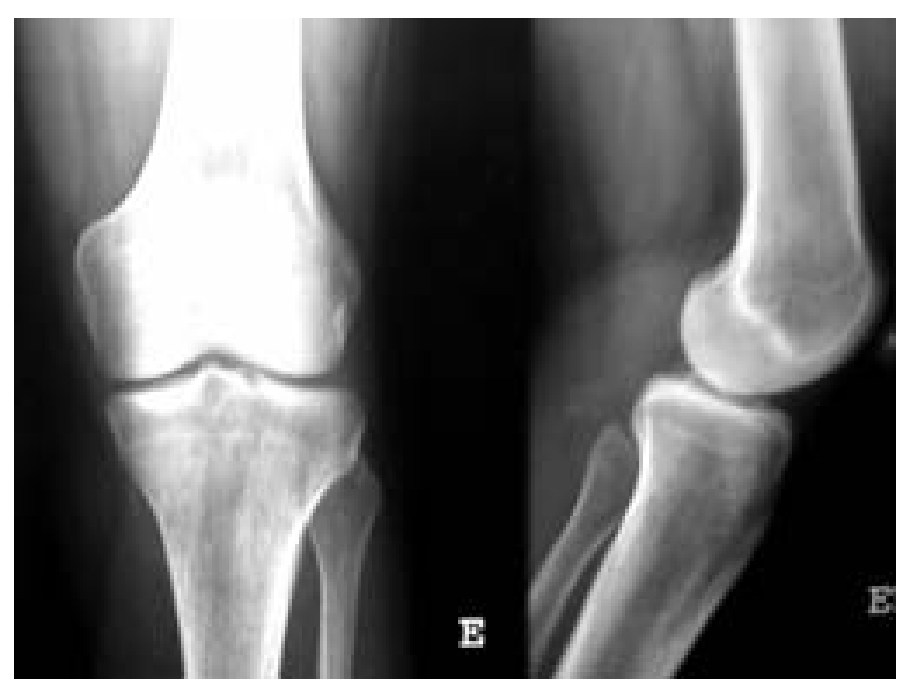

Figura 1 - Radiografia do joelho esquerdo sem alterações

Após avaliação dos exames clínicos e de imagem, a paciente foi submetida à ressecção artroscópica da nodulação, utilizando os portais habituais.

Durante a artroscopia observou-se formação nodular de tecido sinovial de coloração vermelho-marrom, estando fixa por um pedículo ao platô tibial (Figura 3). Não foram encontradas outras lesões associadas.

Um curativo compressivo foi mantido durante os primeiros dias, acompanhado por exercícios para amplitude de movimento. A carga imediata foi permitida conforme a tolerância.

O exame anatomopatológico demonstrou proliferação nodular fibrosa com numerosas células gigantes de permeio, numerosos histiócitos em meio de tecido fibroso denso e deposição focal de fibrina e hemossiderina.

Um programa supervisionado de fisioterapia foi instituído após alta hospitalar e a paciente prosseguiu com um programa domiciliar. Não houve restrição de carga ou uso de muletas. O fortalecimento com exercícios de resistência foi iniciado imediatamente. Após dois meses 

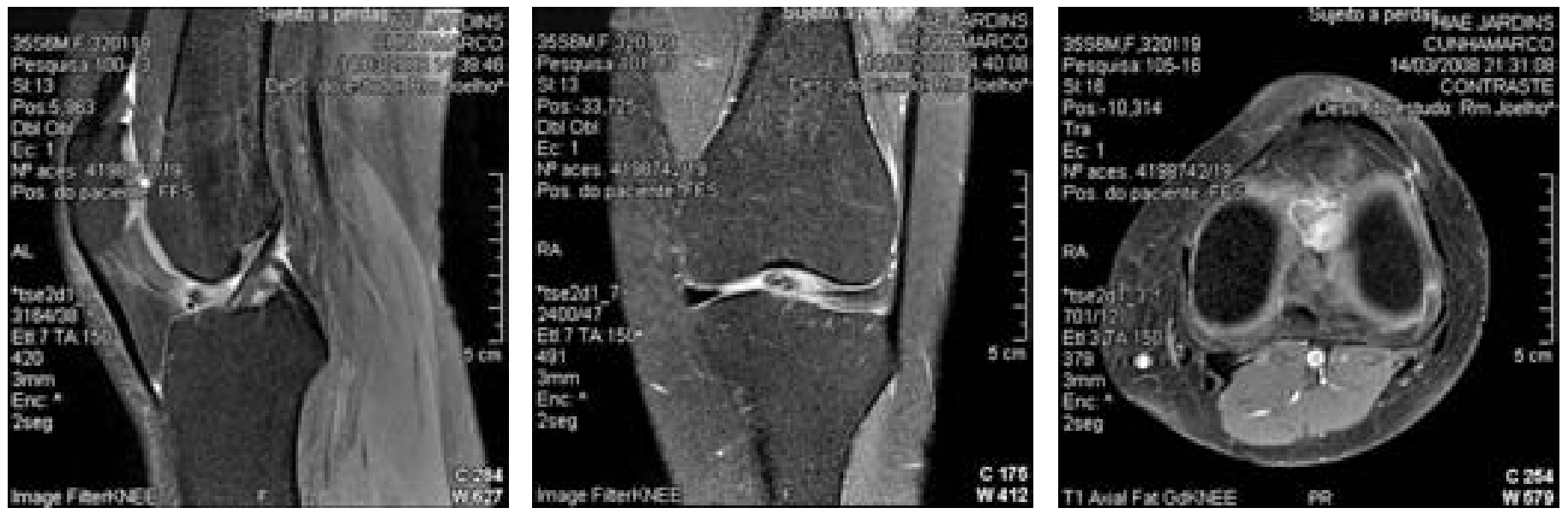

Figura 2A, B e C - RM do joelho E (imagens ponderais em T2 de cortes sagital, coronal e axial) - lesão nodular na porção profunda da gordura de Hoffa, posterior ao ligamento transverso e anterior ao LCA, medindo 1,8 x 1,3cm com baixo sinal em T2
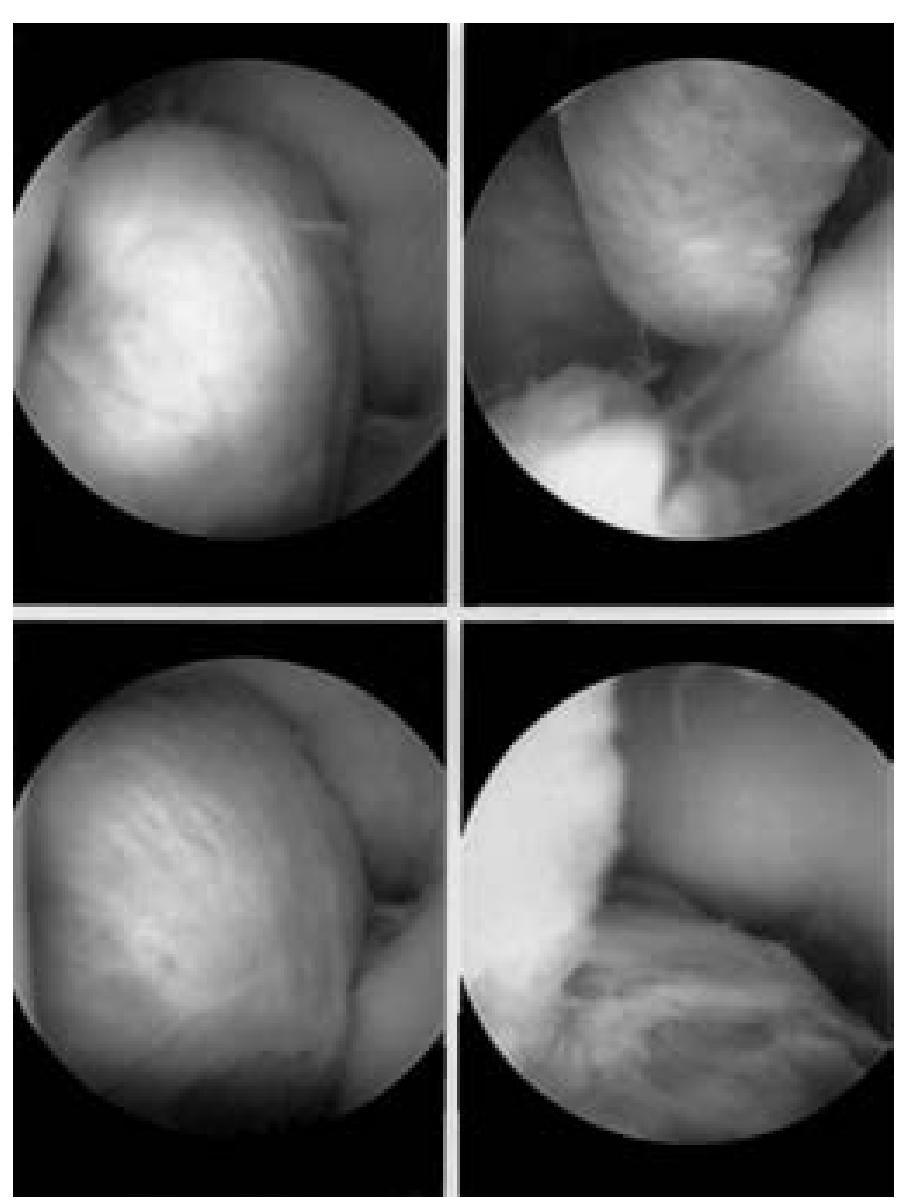

Figura 3 - Aparência macroscópica intraoperatória da lesão: projeção vilosa de formato nodular vermelho-marrom, flutuando no líquido sinovial

de fisioterapia, a paciente retornou a suas atividades habitais, com regressão da dor e da sensação de instabilidade. Os episódios de travamento não se repetiram.

Ao fim de um período de seis meses, repetiu-se a RM, onde não se observou nenhum sinal de recidiva local.

\section{DISCUSSÃO}

Nos relatos iniciais do tumor gigantocelular sinovial do joelho, a nomenclatura era confusa, sendo denominada como: mieloxantoma, artrite vilosa, sinovioma benigno, endotelioma sinovial e artrite vilosa hemorrágica crônica ${ }^{(1)}$. Em 1941, Jaffe et al propuseram o nome de sinovite vilonodular pigmentada, agrupando lesões que mostravam estroma fibroso, deposição de pigmentos, infiltração histiocitária e células gigantes em tecidos sinoviais de articulações, bursas e bainha de tendões ${ }^{(2)}$.

O tumor gigantocelular sinovial é tipicamente uma doença monoarticular, que afeta preferencialmente adultos jovens; as maiores incidências ocorrem na terceira e quarta décadas de vida. Sua taxa de incidência anual estimada é de 1,8 por milhão de pessoas, com igual distribuição por sexo ${ }^{(1,3)}$.

A literatura descreve várias possibilidades etiológicas para justificar o tumor gigantocelular sinovial; entretanto, sua real etiologia permanece incerta. Hiroshima encontrou alto nível de colesterol nos histócitos e postulou que essa condição seria provocada por um distúrbio no metabolismo dos lipídeos. A literatura apresenta outras possibilidades, tais como: processo neoplásico benigno, reação ao estímulo desconhecido e reação a repetidos episódios de trauma ou hemartrose ${ }^{(3,6)}$.

Os tumores sinoviais sob a forma de sinovite vilonodular existem em duas formas distintas: difusa, envolvendo inteiramente o revestimento sinovial; e localizada, mais frequente na junção meniscocapsular. Beguin et al relataram a forma mista, que representaria uma transição entre a localizada e a difusa ${ }^{(7)}$. 
As manifestações clínicas da forma difusa são: dor, derrame, limitação do arco de movimento, que evoluem de forma indolente. O diagnóstico da forma localizada é extremamente difícil, pois os sintomas podem mimetizar uma lesão meniscal ${ }^{(1,3,4)}$.

Sintomas mecânicos como falseio, derrame e edema geralmente estão presentes. A dor é encontrada, porém, de forma imprecisa e raramente intensa.

No tumor gigantocelular sinovial, na forma difusa, podemos encontrar alterações radiográficas, tais como: tumefação e expansão da bolsa sinovial suprapatelar. Na forma localizada não são encontradas alterações radiográficas compatíveis com a doença. A ressonância magnética nesses casos é extremamente útil, pois revela a presença de massa heterogênea, com baixo sinal de intensidade em $\mathrm{T} 1 \mathrm{e} \mathrm{T}^{(3)}$.

O diagnóstico do caso que estamos relatando foi confirmado por estudo histopatológico, que mostrou proliferação de estroma fibroso com infiltração de histiócitos, fibroblastos e células gigantes multinucleadas.

O tratamento preconizado para a sinovite vilonodular pigmentada localizada é a ressecção artroscópica.

Há controvérsias em relação à sinovectomia aberta versus artroscópica. Com qualquer uma das téc- nicas, na forma difusa, a taxa de recorrência varia de $8 \%$ a $50 \%$.

Os benefícios da via artroscópica são reabilitação mais rápida e o fato de se evitar uma artrotomia. As desvantagens estão relacionadas com a realização de um desbridamento intralesional, potencial de disseminação intra-articular da doença, contaminando os sítios dos portais, dificuldade de acesso às localizações posteriores e extra-articulares, e dificuldade de remoção de tecido sinovial espessado ${ }^{(5)}$.

As vantagens de uma sinovectomia aberta em relação à técnica artroscópica são a capacidade de realização de uma excisão marginal, a capacidade de completar uma sinovectomia total e a natureza eficiente de uma artrotomia. Entretanto, um procedimento aberto pode resultar em aderências pós-operatórias ${ }^{(5)}$.

Nenhuma pesquisa prospectiva comparou as duas técnicas; essas pesquisas seriam de difícil realização devido à raridade da doença. É razoável selecionar a técnica artroscópica caso a doença seja nodular focal, e a aberta, quando a doença for difusa ou extra$\operatorname{articular}^{(5)}$.

Portanto, nos parece que a ressecção artroscópica do tumor gigantocelular sinovial, em sua forma localizada, é uma maneira de tratamento eficiente.

\section{REFERÊNCIAS}

1. Asik M, Erlap L, Altinel L, Cetic O. Localized pigmented villonodular synovitis of the knee. Arthroscopy. 2001;17(6):1-6.

2. Jaffe HL, Lichtenstein L, Sutro CJ. Pigmented villonodular synovitis. Arch Pathol Lab Med. 1941;31:731-65.

3. Kim SJ, Shin SJ, Choi NH, Choo ET. Artroscopic tratament for localized pigmented synovitys of the knee. Clin Orthop Relat Res. 2000;(379):224-30.

4. Muscolo DL, Makino A, Costa-paz M, Ayerza M. Magnetic resonance imging and arthoscopic resection of localized pigmented villonodular synovitis of the knee.

Orthopedics. 2000;23(4):367-9.

5. Peterson L. Chondrocyte transplantation. In: Douglas WJ. Reconstructive knee surgery-master techniques in orthopaedic surgery. New York: Lippincott Williams and Wilkins;2005. p.427-39

6. Ogilvie-harris DJ, McLean J, Zarnett ME. Pigmented villonodular synovitis of the knee, and arthroscopic local excision.J Bone Joint Surg Am. 1992;74(6):952.

7. Beguin J, locker B, Vielpeau C. Pigmented villonodular synovitis of the knee results from 13 cases. Arthroscopy.1989;5(1):62-4. 